$\xi=-1$

\title{
Rock Physics Modeling Assisted Reservoir Properties Prediction: Case Study in Malay Basin
}

\author{
Amir Abbas Babasafari ${ }^{1}$, Deva Ghosh ${ }^{2}$, Ahmed M. A. Salim ${ }^{3}$, S.Y. Moussavi Alashloo ${ }^{4 *}$ \\ 1,2,3,4 Center of Seismic Imaging, Department of Petroleum Geoscience, \\ Universiti Teknologi Petronas (UTP), Bandar Seri Iskandar, Malaysia \\ *Corresponding Author Email: y.alashloo@gmail.com
}

\begin{abstract}
Shear velocity log is not measured at all wells in oil and gas fields, thus rock physics modeling plays an important role to predict this type of log. Therefore, seismic pre stack inversion is performed and elastic properties are estimated more accurately. Subsequently, a robust Petro-Elastic relationship arising from rock physics model leads to far more precise prediction of petrophysical properties. The more accurate rock physics modeling results in less uncertainty of reservoir modeling. Therefore, a valid rock physics model is intended to be built. For a better understanding of reservoir properties prediction, first of all rock physics modeling for each identified litho-facies classes should be performed separately through well log analysis.
\end{abstract}

Keywords: Litho-facies, reservoir modeling, reservoir properties prediction, rock physics modeling, petrophysical properties

\section{Introduction}

Reservoir modeling is a significant step for a successful performance of development and production of oil and gas fields. Therefore, an accurate reservoir model allow us to have correct production forecast and reduce the uncertainties and drilling risks. The objective of this study is development of a new concept in rock physics modeling.

The studied area is located in the Malay Basin (Figure 1) which consists of several other discovered gas fields from the Group B, $\mathrm{D}$ and $\mathrm{E}$ and the oil in the Group E. The stratigraphic group E and $\mathrm{D}$ are the main reservoirs in the Northern Malay Basin. Group E sandstone reservoirs are mostly fluvial channel sediments that deposited in a lower coastal plain setting. The field of study is an east-west trending anticline intersected by numerous north-south normal faults and a major east-west trending normal fault. Oil show has displayed in some wells. Due to distribution of sand patches as a component of stratigraphy traps in the field, the presence of oil rim has not been disproved. Masking of sand stone reserves in seismic imaging by numerous coal beds, thin bed reservoir layers and gas cloud adverse effect on seismic data are among major issues to tackle. [1]

\section{Methodology}

\subsection{Litho-Facies Classification at Well Locations}

Determination of cut off value through petrophysical evaluation of well logs resulted in litho facies classification at well locations. Mineralogy volumes, water saturation and effective porosity logs is utilized for this purpose and 4 main facies are classified in this study: shale, wet sand, gas sand and coal.

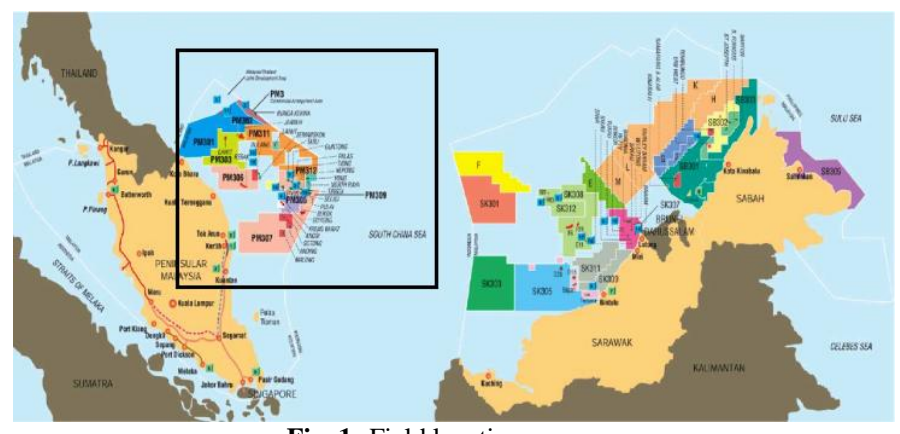

Fig. 1: Field location map

\subsection{Rock Physics Modeling}

The dependency of seismic velocity to reservoir properties such as litho facies, porosity, fluid saturation and pore pressure has been distinguished. [2]

In fact Rock physics model relates the elastic properties of a rock to its petrophysical properties. (Petro-Elastic Model)

A Rock Model is needed to be created once the well logs are conditioned and edited. The mentioned model is used to derive the elastic rock properties from mineral parameters, structure information and fluid.

A rock physics model should simulate reservoir properties such as mineral grain volume, porosity, pore fluid, pressure, pore shape, pore size, cementation, number of grain contacts and... properly by utilizing appropriate equations in order to enable us to predict elastic properties per defined facies with less uncertainty.

To clarify the research objectives, Figure 2 illustrates the relationships among seismic data, elastic properties and reservoir modeling. [3] 


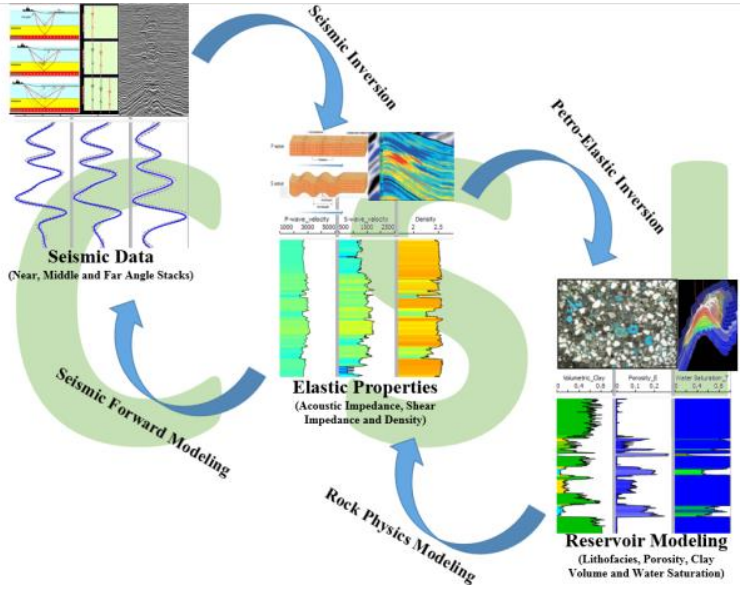

Fig. 2: Relationships among seismic data, elastic properties and reservoir modeling

The rock physics model is implemented in an Effective Medium using Granular model. This model can be used to model unconsolidated sandstone reservoirs saturated with hydrocarbon and brine. [4]

It is assumed a dense random pack of spherical grains with a given critical porosity for the initial framework of this model.[5]

This methodology is according to a theory suggested by Dvorkin and Nur (1996) [6] and Ødegaard and Avseth (2003) [7]. Ødegaard and Avseth (2003) proposed a technique they called the Rock Physics Template (RPT), offered by Dvorkin and Nur (1996), in which the mineralogical volume changes and fluid of a reservoir is illustrated on a cross plot acoustic impedance versus $\mathrm{Vp} / \mathrm{Vs}$ ratio, as shown in Figure 3 .

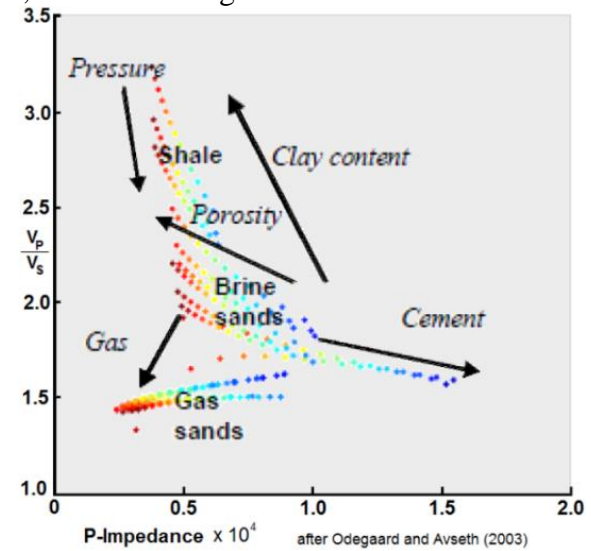

Fig. 3: Reservoir property changes within Vp/Vs ratio vs. acoustic impedance cross plot

The Ødegaard and Avseth RPT demonstrates computation of the $\mathrm{Vp} / \mathrm{Vs}$ ratio and P-Impedance of various rock types based on their mineralogy, porosity, fluid type, pressure and grain contacts.

In this study Petro-Elastic Model summarized in four major steps:

1. Calculation of dry rock bulk modulus using the HertzMindlin theory [8]

2. Computing the dry rock modulus over a range of porosities by the lower Hashin-Shtrikman bound.

3. Gassmann Fluid substitution.

4. Elastic properties prediction (Density, P-wave velocity, $\mathrm{S}$-wave velocity) for each scenario and cross-plotting $\mathrm{P}$ impedance versus $\mathrm{Vp} / \mathrm{Vs}$ ratio.

Rock Physics Modeling procedures in this study are elaborated as follow:
The matrix bulk moduli is determined by mineral grains volume and on how the grains and pores are arranged relatively. The matrix mixed mineral bulk modulus $(\mathrm{Km})$ and shear modulus $(\mu \mathrm{m})$ is calculated using the Reuss relation. The Reuss (harmonic averaging) simulates a homogeneous distribution of the minerals composing the matrix. Afterwards, the bulk and shear moduli at the critical porosity are computed with the Hertz Mindlin contact theory.

Hertz-Mindlin theory assumptions are:

- The strains are not remarkable.

- The grains are isotropic, elastic, identical and homogeneous.

- The grain packing is random.

- The given elastic constants are only relevant for the propagation of wavelengths much longer than the grain radius.

Critical porosity is the porosity which separates the suspension (fluid with grains in suspension) and load-bearing (rocks with fluid in the pores) domains. Standard values are between 0.36 and 0.40. It occurs in Hertz-Mendilin contact theory conditions.

Bulk moduli was computed by Hertz for two similar grains. (Figure 4-left) and by adding the tangential force, the effective shear moduli was computed by Mendilin (Figure 4-right).

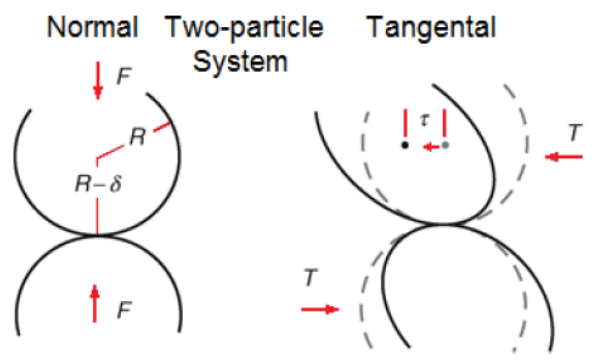

From Mavko et al., 2009

Fig. 4: Displacement of a two-particle system, Normal (left) and tangential (right) (From Mavko et al., 2009)

The final terms required in Hertz-Mindlin (HM) contact theory:

$$
\begin{aligned}
& K_{H M}=\left[\frac{C^{2}\left(1-\varphi_{c}\right)^{2} \mu_{m}{ }^{2} p_{e f f}}{18 \pi^{2}\left(1-v_{m}\right)^{2}}\right]^{\frac{1}{s}} \\
& \mu_{H M}=\frac{4-4 v_{m}}{5\left(2-v_{m}\right)}\left[\frac{3 C^{2}\left(1-\varphi_{c}\right)^{2} \mu_{m}{ }^{2} p_{e f f}}{2 \pi^{2}\left(1-v_{m}\right)^{2}}\right]^{\frac{1}{3}}
\end{aligned}
$$

Where: Peff $=$ Effective pressure, $\mathrm{Km}=$ mineral bulk moduli, $\mu \mathrm{m}$ $=$ mineral shear moduli, $v \mathrm{~m}=$ mineral poisson's ratio, $\varphi \mathrm{c}=$ Critical porosity end member, and $\mathrm{C}=$ contacts per grain

Effective pressure is calculated using the following equation (Terzaghi equation):

Effective pressure $=$ Lithostatic pressure - Pore pressure

Friction coefficient parameter which describes the amount of friction between the grains and Grain angularity which shows average radius ratio between the matrix grains are used in extended Hertz Mindilin equations.

Next we extend the Hertz-Mindlin values to all porosity ranges through using the lower Hashin-Shtrikman bound and Kdry is extracted. [9]

Kdry is the bulk modulus of the dry rock frame. The dry rock is not the same as the gas-saturated rock. The dry rock modulus rep- 
resents increment of bulk deformation arising from an increase of applied confining pressure with constant pore pressure. At reservoir conditions (high pore pressure), gas takes on a small but nonzero bulk modulus.[10]

By taking the pressure effects on samples of a dry and saturated rock into consideration, Mavko and Mukerji (1995) concisely display how the Gassmann equation can be extracted. [11]

Subsequently, the effective bulk modulus is computed with Gassmann's equation. [12]

$\frac{K_{\text {sat }}}{K_{m}-K_{\text {sat }}}=\frac{K_{\text {dry }}}{K_{m}-K_{\text {dry }}}+\frac{K_{f}}{\varphi\left(K_{m}-K_{f}\right)}$

Ksat is the saturated bulk modulus of the rock. This saturated bulk modulus can be expressed as function of the porosity $(\varphi)$, of the bulk modulus of the matrix $(\mathrm{Km})$, of the bulk modulus of the fluids (Kf) and of the bulk modulus of the dry rock (Kdry)

Where:

$\mathrm{Km}$ depends on the mineralogical composition and on how the mineral grains and pores are arranged relatively to each other.

$\mathrm{Kf}$ depends on the fluid composition and on the PVT properties in the reservoir.

For uniform saturation of mixed fluids, gas, oil and brine phases are mixed uniformly at a very small scale, as such that the different wave-induced increase has time to equilibrate within a seismic period. The pore-fluid bulk modulus can be expressed with the Reuss average equation. Therefore, the Reuss averaging was chosen to compute the fluid bulk modulus (Kf)

$1 / \mathrm{Kf}=$ Swater/Kwater + Soil $/$ Koil + Sgas $/$ Kgas

Swater, Soil and Sgas are the saturations of water, oil and gas respectively, and, Kwater, Koil and Kgas are bulk moduli of water, oil and gas. Fluid bulk moduli are estimated as described by Batzle and Wang (1992). They are function of pressure, temperature and fluid composition. [13]

Gassmann model assumptions are:

- Valid for isotropic rock.

- Rather similar aspect ratio of pore space.

- Pore pressure remains constant during seismic wave propagation.

$\mu$ sat is the saturated shear modulus of the rock. In Gassman's relations, the shear modulus is unaffected by fluids, hence

$\mu \mathrm{sat}=\mu \mathrm{dry}$

The density is computed as the volumetric average of a mix of quartz and clay. $\rho$ sat is the saturated density of the rock. This saturated rock density depends on the densities pfluid and on the saturations Sfluid of the fluids present in the rock, but it also depends on the matrix density pmatrix and on the porosity $(\varphi)$

$\rho$ sat $=$ pmatrix $(1-\varphi)+$ pfluid $\varphi$, pfluid $=\rho$ waterSwater $+\rho$ hc $(1-$ Swater), $\varphi=$ porosity

The density and bulk modulus of the different fluids are computed with Batzle \& Wang's equations.

Eventually, compressional and shear velocity are computed using following equations:

$V_{p_{\text {sat }}}=\sqrt{\frac{K_{\text {sat }}+\frac{4}{\mathrm{~g}} \mu_{\text {sat }}}{\rho_{\text {sat }}}}$
$V_{s_{-} s a t}=\sqrt{\frac{\mu_{\text {sat }}}{\rho_{\text {sat }}}}$

\section{Results and Discussion}

RockSI module of Hampson Russell software is used for obtaining the results. Petro-Elastic Model is used to predict elastic well logs derived from petrophysical logs. The created Rock Physics Model (RPM) is optimized through adjusting the predicted and measured elastic log data.

This is carried out by overlay comparison of predicted logs (red) and measured logs (black) in vertical section (Figure 5) and also different cross plots per defined facies (Figure 7). Comparison of probability distribution function between predicted and measured data aids to evaluate Petro-Elastic Model (PEM) statistically. The next quality control step is compared by overlaying real seismic data (blue) and synthetic data (red) generated from predicted elastic logs (compressional velocity, shear velocity and density) using Zoeppritz equations for creation of near, middle and far angle stacks. (Figure 5) Far angle stack data demonstrates that a preconditioning on angle gather are required to be done.

Apart from coal prediction which is estimated roughly due to input data (discrete value of coal mineral volume which is 0 or 1 and not continuous such as clay or quartz mineral volumes), the rest three litho facies types are predicted sufficiently. Coal prediction will be enhanced through using Monte Carlo Simulation.

Once the Petro-Elastic Model (PEM) has been calibrated, it is possible to generate Rock Physics Templates (RPT) for each litho facies. These can be visualized in cross-plots superimposed with log data or inversion results aim to assess the relationship between lithology, porosity or fluid saturations and seismic velocities. (Figure 6)

In the next stage Monte Carlo simulation is applied to create more efficient litho facies classification through Petro-Elastic Model.

a)

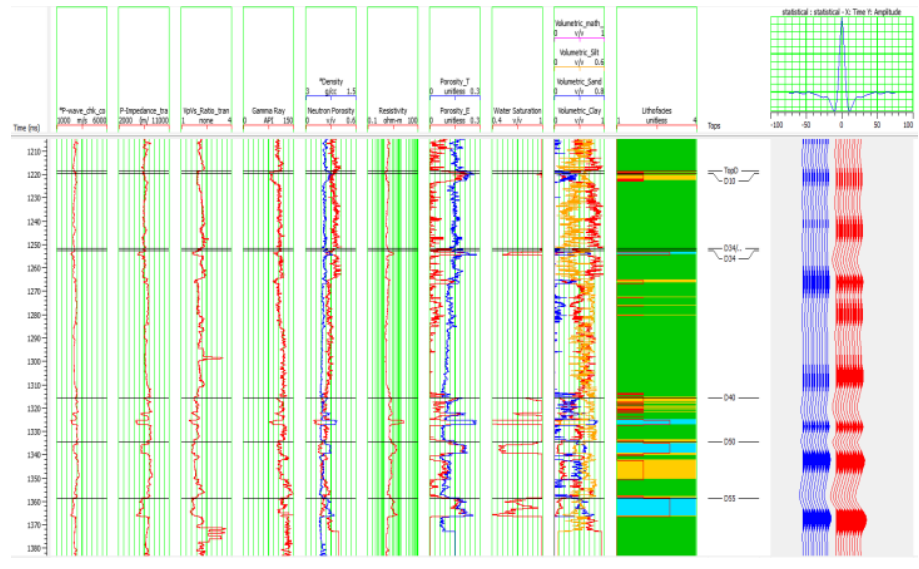


b)

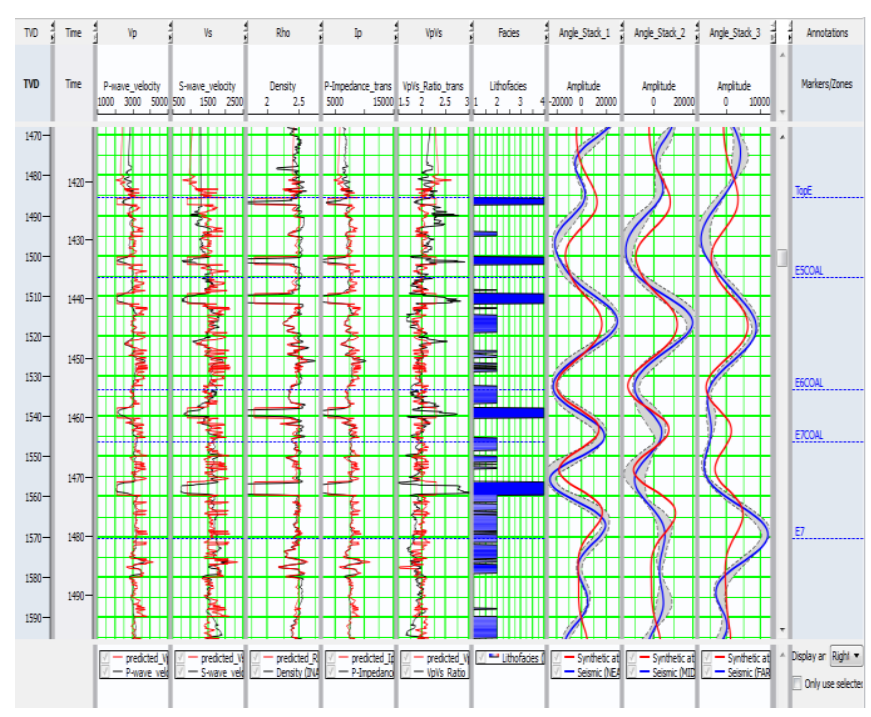

Fig. 5: Litho-facies classification using petrophysical well logs (a-left), correlation of seismic (red) and synthetic (blue) post stack data (a-right), overlay comparison of predicted logs (red) and measured logs (black) (bleft), overlay comparison of real angle stacks seismic data (blue) and synthetic data (red) (b-right) in vertical section

In this study, rock physics modeling is employed to estimate elastic properties from petrophysical logs. A robust Petro-Elastic relationship for each identified litho-facies classes is established in an Effective Medium using Granular Model. This model can be utilized to simulate unconsolidated sandstone reservoirs saturated with hydrocarbon and brine. It is assumed a dense random pack of spherical grains with a given critical porosity for the initial framework of this model. First matrix mixed mineral bulk modulus is computed using Reuss relation. Then, dry rock bulk modulus for each litho-facies is calculated by the Hertz-Mindlin contact theory. Afterwards, dry rock modulus over a range of porosities by the lower Hashin-Shtrikman bound is obtained. Applying Gassmann Fluid Substitution results in Elastic properties prediction (Density, P-wave velocity, S-wave velocity). Finally, P-impedance versus $\mathrm{Vp} / \mathrm{Vs}$ ratio is cross plotted. The predicted elastic properties results are evaluated based on Ødegaard and Avseth RPT methodology in which cross-plotting of P-Impedance versus $\mathrm{Vp} / \mathrm{Vs}$ ratio for different litho-facies classes demonstrates petrophysical properties variation includes shale content, porosity and fluid saturation. (Figure 3 and 7)

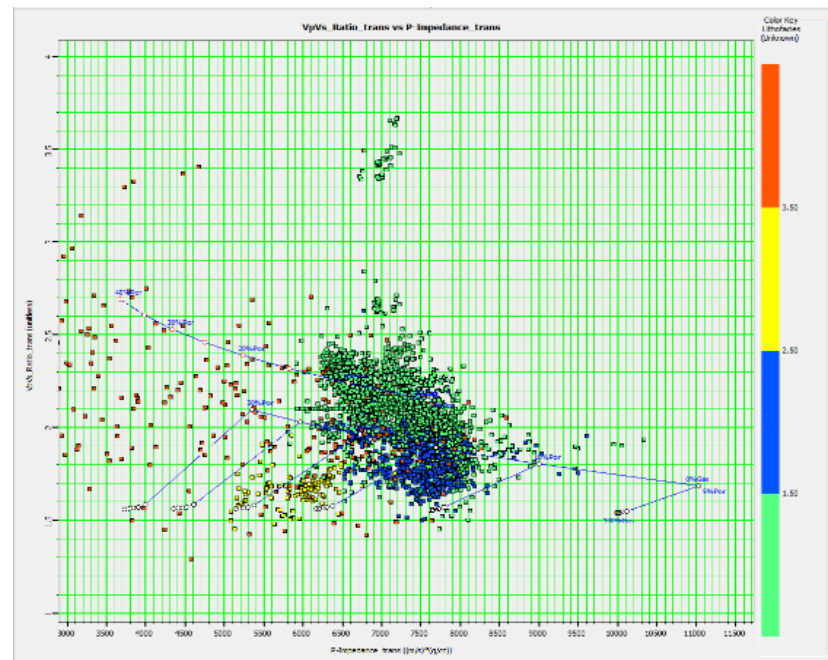

Fig. 6: Shale line and sand Rock Physics Template (RPT) superposition on P-Impedance (x-axis) vs. Vp/Vs (y-axis) cross plot
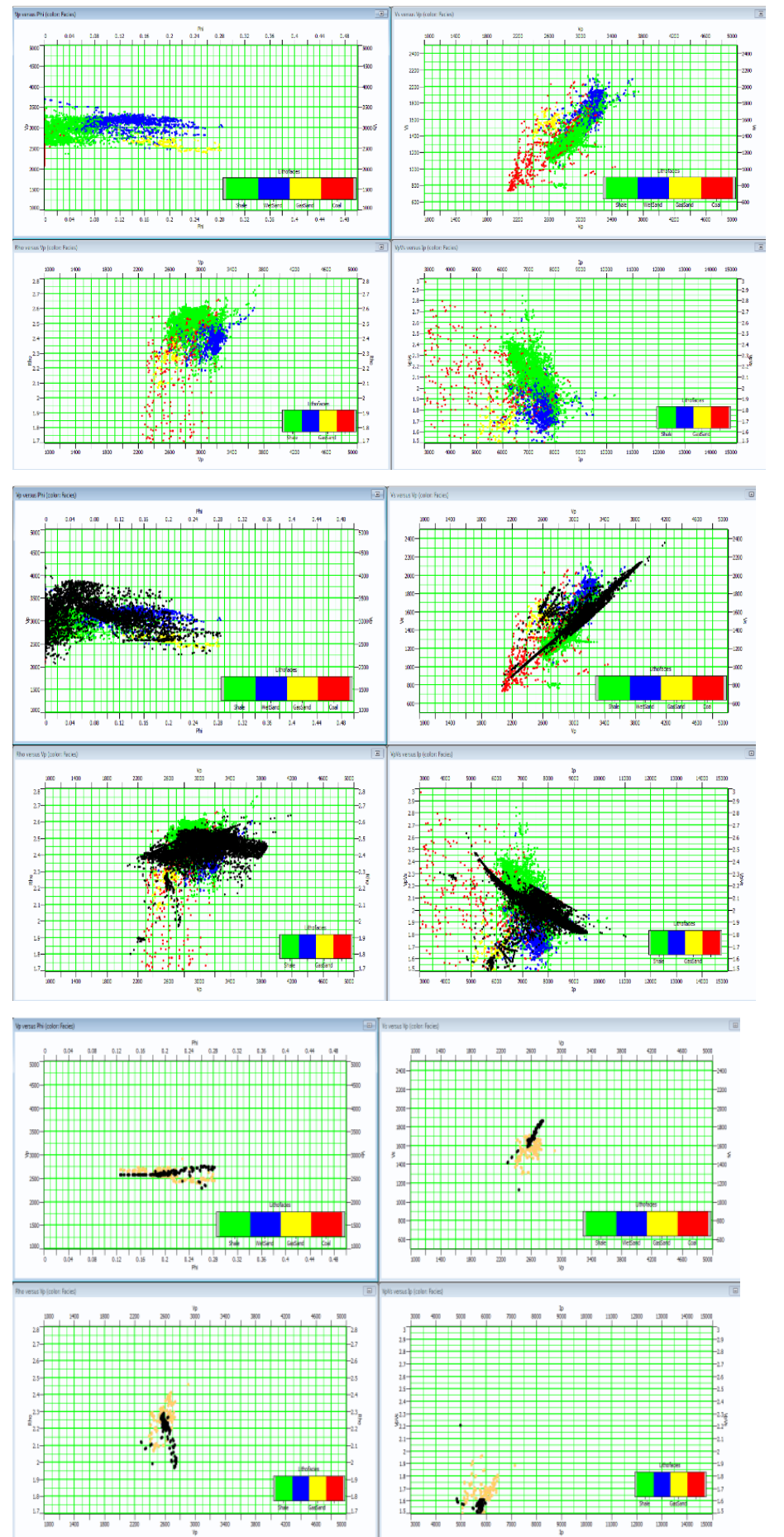

Fig. 7: Petro-Elastic properties cross plots of 4 different color code litho facies (left to right, top to bottom: Phi vs. Vp, Vp vs. Vs, Vp vs. Rho, Ip vs. $\mathrm{Vp} / \mathrm{Vs}$ ) (top), Overlay comparison cross plots of measured PetroElastic properties ( 4 color codes) and predicted elastic properties (black) (middle) and Overlay comparison cross plots of measured Petro-Elastic properties (e.g. gas sand) and predicted elastic properties (black) (bottom)

\section{Conclusion}

Rock physics modeling play an important role to predict elastic logs, particularly the oil and gas field in which shear wave data is not measured at all wells. The quality control steps of overlay comparison which discussed in this article should be taken into account. Definitely, more accurate pre stack seismic inversion will be concluded. Furthermore, the Petro-Elastic Model after well data calibration can be used for a remarkable quantitative reservoir modeling. 


\section{Acknowledgement}

We would like to express our gratitude to CSI/UTP for valuable resources and also Petroliam Nasional Berhad (PETRONAS) for providing the necessary information and proprietary data for this study.

\section{References}

[1] Ghosh D., Halim MFA, Brewer M and Viratno B (2010), "Geophysical issues and challenges in Malay and adjacent basins from an E \& P perspective," Leading Edge, vol. 29, pp. 436-449.

[2] Ghosh D., Babasafari A., Ratnam T., and Sambo C. (2018), "New Workflow in Reservoir Modelling - Incorporating High Resolution Seismic and Rock Physics", Offshore Technology Conference. doi:10.4043/28388-MS.

[3] Ghosh D., Sajid M and Ibrahim NA (2014), "Seismic attributes add a new dimension to prospect evaluation and geomorphology offshore Malaysia," Leading Edge, vol. 33, pp. 536-545.

[4] Avseth P, Mukerji T, Mavko G (2010), "Quantitative seismic interpretation: Applying rock physics tools to reduce interpretation risk" Cambridge University Press.

[5] Johansen, A., Jensen, E., Mavko, G., and Dvorkin, J. (2013), “Inverse rock physics modeling for reservoir quality prediction" Geophysics, vol. 78, No. 2, P. M1-M18.

[6] Jensen, E., Johansen, A., Avseth, P. and Bredesen, K. (August 2016), "Quantitative interpretation using inverse rock-physics modeling on AVO data", The Leading Edge.

[7] Bredesen, K., Jensen, E., Johansen, T. and Avseth, P. (2015), "Quantitative seismic interpretation using inverse rock physics modelling", Petroleum Geoscience.

[8] Russell B. (2014), "Rock Physics Templates".

[9] Russell B. and Smith T. (2007), "The relationship between dry rock bulk modulus and porosity-an empirical study," CREWES Res. Rep., vol. 19, pp. 1-14.

[10] Russell B. (2013), “A Gassmann-consistent rock physics template,' in CSEG Recorder, pp. 22-30

[11] Mavko, G., Mukerji, T., and Dvorkin, J. (2009), “The Rock Physics Handbook: Tools for Seismic Analysis of Porous Media" Cambridge University Press.

[12] Avseth, P., Jørstad, A.,van Wijngaarden, A. J., and Mavko, G. (2009), "Rock physics estimation of cement volume, sorting, and net-to-gross in North Sea sandstones" The Leading Edge, 28, 98 108.

[13] Dvorkin, J., Gutierrez, M. A., and Grana, D. (2014), "Seismic reflections of rock properties" Cambridge University Press. 